\title{
Microbial Fertilizer Improves Constitutive and Induced Resistance of Tomato against a Generalist Insect
}

\author{
Sharma G' ${ }^{1}$, Anjulo $\mathrm{MT}^{2}$ and Mathur V1* \\ ${ }^{1}$ Department of Zoology, Sri Venkateswara College, University of Delhi, India \\ ${ }^{2}$ School of Plant and Horticultural Sciences, Hawassa University, Hawassa, Ethiopia \\ *Corresponding author: Vartika Mathur, Department of Zoology, Sri Venkateswara \\ College, Benito Juarez Marg, Dhaula Kuan, New Delhi-110021, India, Tel: \\ +919810386575; Email: vartika_m@yahoo.com
}

\section{Research Article \\ Volume 2 Issue 1}

Received Date: January 02, 2019

Published Date: January 24, 2019

DoI: $10.23880 /$ izab-16000135

\section{Abstract}

Plants express various constitutive and induced resistance mechanisms that require substantial share of plant nutrients. Microbial fertilizers such as Phosphate Solubilizing Bacteria (PSB) are known to enhance nutrient availability to the plant, thereby helping in plant growth. However, it is still unknown whether such a growth compromises plant resistance. In present study, we evaluated the effect of PSB on early as well late responses in tomato (Solanum lycopersicum) after damage by Spodoptera litura. We also studied whether these responses translate to resistance mechanisms by analyzing response of insect larvae on damaged plants. Our results indicate that, at early hour both unsupplemented and plants supplemented by PSB showed equal susceptibility towards insect induced oxidative damage. From 48h onwards elevated resistance mechanisms were observed in PSB-supplemented plants, especially increase in trichome numbers and shoot biomass. Moreover, decreased feeding preference of larvae was also observed on the previously damaged PSBsupplemented plants. However, an increased consumption index does indicate increased palatability of the plant, possibly due to high phosphorus availability. Our results thus indicate that PSB administration improves growth as well as induced resistance in tomato.

Keywords: Spodoptera Litura; Phosphate Solubilizing Bacteria; Induced Systemic Resistance; Antioxidants; Insect behaviour

Abbreviations: PSB: Phosphate Solubilizing Bacteria; PGPMs: Plant Growth Promoting Microorganisms; IARI: Indian Agricultural Research Institute; SOD: Enzymes Superoxide Dismutase; GR: Glutathione Reductase PPO: Polyphenol Oxidase; PMSF: Phenyl Methyl Sulfonyl Fluoride.

\section{Introduction}

Plants encounter variety of insects in their natural environment, for which they have developed constitutive and induced defence system. Constitutive defenses are not as common in annual plants and where, there are small and unpredictable insect communities, due to their high cost $[1,2]$. In effect, these plants rely on inducible defenses as a cost saving strategy $[1,3]$. However, even inducible defenses may result in fitness costs such as decreased fruit production [4]. A major drawback of such defenses is that the plant remains susceptible in the long period between the initial damage and the peak of defense response [3]. Further, various environmental features are considered to affect allocation of plant 


\section{International Journal of Zoology and Animal Biology}

resources to defensive compounds [5,6]. In view of these evidences, nutrient accessibility becomes a vital factor in influencing the allocation of the available resources and hence the plant growth [5,7]. In agricultural systems application of fertilizers is considered as a fundamental method of improving soil nutrient availability for plants [7-10].

Phosphorus is one of the most essential macronutrients for plant growth and development [11]. However, in soil, most of it is present in bound form and thus is a major limitation for plant growth [12]. A large portion of soluble inorganic phosphate that is applied to soil as chemical fertilizer is immobilized after application, or may runoff and thus becomes unavailable to plants $[13,14]$. A promising alternate to synthetic fertilizers is the use of Plant Growth Promoting Microorganisms (PGPMs) such as phosphate solubilizing bacteria (PSB). PSB play a central role in mineralization of most organic phosphorous compounds using phosphatase enzymes from inorganic and organic pools of the total soil phosphorus $[15,16]$. However, they secrete organic acids such as acid phosphate, gluconic acid and malic acid, which affect plant's physiology, growth and yield $[17,20]$. Several reports also suggest that due to their presence in the plant rhizosphere, PGPMs might also help in inducing plant's resistance to phytopathogens insect pests and nematode pests [17,21-24].

Tomato (Solanum lycopersicum L.) is the second most important vegetable crop in the world. It occupies about 3.7 million hectares agriculture area worldwide that produces approximately 100 million tons fresh fruit annually [25]. However, despite its global importance in diet, very few studies have dealt with the factors that affect its production in areas that are prone to stress conditions such as drought, salinity, nutrient deficiency, weeds and insect pests [26,27]. Many studies suggest improved health and immunity in tomato when supplemented with PGPMs due to the increased availability of primary nutrients [28-30]. However, their effect on plant resistance mechanism is still not known. Therefore in present study, we evaluated the effect of PSB on the constitutive and induced resistance mechanisms in tomato during damage by Spodoptera litura. Biochemical (antioxidants and chlorophyll), morphological (trichomes) and physiological (dry weight) parameters were studied in plants with and without PSB supplementation. Furthermore, preference as well as feeding and performance of $S$. litura was also examined on damaged and undamaged plants treated with or without PSB in order to determine whether these responses may be translated as resistance mechanisms.

\section{Materials and Methods}

\section{Plant}

Seeds of S. lycopersicum var. PH-4 were obtained from Indian Agricultural Research Institute (IARI), New Delhi, India. The seeds were initially germinated on glass beads in $10 \times 10 \mathrm{~cm}$ plastic containers inside the plant growth chamber at $27 \pm 1^{\circ} \mathrm{C}, 65 \pm 5 \% \mathrm{RH}$ and 16 : $8 \mathrm{~h}$ light/dark photoperiod. The plants of stage 11 as per BBCH scale Lancashire, et al. [31] were transferred to 6 inch earthen containing garden soil with vermicompost in 3:1 ratio inside the insect free enclosure at Sri Venkateswara College. For plant growth in pots, $1 \mathrm{Kg}$ of soil was mixed with $10 \mathrm{ml}$ of a commercial PSB formulation Phosphophix® (International Panaacea Pvt. Ltd, New Delhi, India) containing Bacillus megaterium, Pseudomonas fluorescence and Bacillus spp. Equal number of control plants was given soil mixed with $10 \mathrm{ml}$ of double distilled water instead of PSB formulation.

\section{Insect}

S. litura was obtained from laboratory cultures maintained in Animal Plant Interactions lab at Sri Venkateswara College, University of Delhi. The insects were periodically supplemented with field collected population to avoid inbreeding. Insects were maintained at a constant temperature of $27 \pm 1^{\circ} \mathrm{C}$ with $75 \pm 5 \% \mathrm{RH}$ and 16:8h light/dark photoperiod on castor leaves sterilized with $\mathrm{K} 2 \mathrm{MnO} 4$. The adults were provided with $10 \%$ honey solution with multivitamins.

\section{Induction of Plants}

The experiments were conducted on plant stage 25 according to BBCH scale. Single third instar S. litura was introduced in a $2.5 \mathrm{~cm}$ plastic clip cage on the third true leaf of the plant. Undamaged treatments of PSB supplemented and control plants received empty clip cages on its third true leaf for the undamaged treatment set. The damaged and undamaged plants were arranged randomly in the insect free enclosure. Insects were allowed to feed on the plant for $48 \mathrm{~h}$, unless mentioned otherwise. Based on the preliminary Rhodamine B dye tracking study, fifth leaf was used for the study responses. Following induction, plants were studied for morphological, physiological and biochemical parameters at various time points.

\section{Trichome Number}

Glandular and non-glandular trichomes were counted on the adaxial and abaxial surface of the leaf according to 0 'Neal, et al. [32]. Two spots of $1 \mathrm{~cm} 2$ each were used to 


\section{International Journal of Zoology and Animal Biology}

count the trichomes and their mean values were used for analysis.

\section{Fresh and Dry Weight}

Fresh and dry weight study was done on plants of stage 41 according to BBCH scale in a set of 20 replicates. Insect induction of each set of the four sets of plant was done for $48 \mathrm{~h}$ which was followed by uprooting and separation into root and shoot parts. The root part was washed with distilled water to remove loose soil and carefully blotted with filter paper to remove surface moisture only. The plant parts were then weighed separately and placed individually in paper bags for drying in oven at $60^{\circ} \mathrm{C}$. The dry weight of the plants was observed after $48 \mathrm{~h}$.

\section{Antioxidant Estimation}

Extraction of antioxidants from each of the four set of plants was done after $3 \mathrm{~h}$ and $9 \mathrm{~h}$ of $S$. litura damage. The single leaflet was removed, weighed and homogenized in $2 \mathrm{ml}$ extraction buffer containing $0.6 \%$ polyvinyl propylidine, $10 \mathrm{mM}$ EDTA, $10 \mathrm{mM}$ cystein and $100 \mathrm{mM}$ Tris $\mathrm{HCl}$ in ice cold conditions. The homogenized leaf was centrifuged in $10,000 \mathrm{rpm}$ for $10 \mathrm{~min}$ in $4^{\circ} \mathrm{C}$. The pellet was discarded and supernatant was immediately stored on $20^{\circ} \mathrm{C}$ until further use. The leaf extract thus obtained was used to study the enzymes Superoxide dismutase (SOD), Glutathione reductase (GR) and Polyphenol oxidase (PPO).

SOD was analysed as per Verma, et al. [33] using $10 \mu \mathrm{l}$ of leaf extract with $100 \mathrm{mM}$ sodium phosphate buffer $(\mathrm{pH}$ 7.4 ), $20 \mathrm{mM}$ methionine (prepared in $0.1 \mathrm{ml}$ of $1 \%(\mathrm{v} / \mathrm{v}$ ) Triton X-100), 10mM Hydroxylamine hydrochloride and $100 \mu \mathrm{M}$ EDTA. After incubation at $37^{\circ} \mathrm{C}$ for $5 \mathrm{~min}$ in dry bath, $100 \mu \mathrm{M}$ riboflavin was added to the mixture and reaction was initiated by incubated under 20W fluorescent light at room temperature. The reaction was stopped using Greiss reagent and the absorbance was taken at $543 \mathrm{~nm}$ against no enzyme and no riboflavin control. SOD was calculated using the following equation:

SOD units $/$ ug of protein $=\frac{[\text { O.D. of control } /(\text { O.D. of sample }-1)]}{10 \text { ug of protein }}$

GR activity was studied at $340 \mathrm{~nm}$ used in the reaction mixture containing $100 \mathrm{mM}$ Tris- $\mathrm{HCl}$ buffer (pH 7.8), $0.5 \mathrm{mM}$ Glutathione disulphide (GSSG), 2mM EDTA and $0.2 \mathrm{mM}$ NADPH along with the leaf extract, as per Rao, et al. [34]. Enzyme activity was studied for 3 min duration with an interval of 12 seconds using UV-Vis spectrophotometer (Shimadzu UV-1800, Shimadzu, Japan).
For PPO analysis, the insect induction was given for 48h. $0.1 \mathrm{~g}$ of leaf was flash freezed in liquid nitrogen and homogenized with $50 \mathrm{mM}$ Sodium phosphate buffer $\mathrm{pH}$ 6.0). The sample was vortexed for $5 \mathrm{~min}$ and centrifuged at $10000 \mathrm{rpm}$ for $15 \mathrm{~min}$ at $4^{\circ} \mathrm{C}$. Supernatant was transferred to a new eppendorf tube and centrifuged at $10000 \mathrm{rpm}$ for $30 \mathrm{~min}$ at $4^{\circ} \mathrm{C}$. The final supernatant was used for PPO estimation. $100 \mathrm{mM}$ phenyl methyl Sulfonyl fluoride (PMSF) was added before analysis. $30 \mu$ of leaf extract sample was pipetted in a well of the 96 microliter well plate in a $200 \mu$ reaction mixture containing $5.75 \mathrm{mM}$ L-DOPA and $100 \mathrm{mM}$ sodium phosphate buffer ( $\mathrm{pH} 8.0$ ). The reaction was performed on ice in dark conditions. The kinetic rate reading of the reaction was taken at $490 \mathrm{~nm}$ at 1 minute interval for 10 minutes using the ELISA plate reader (Electronics Corporation of India, India) and was calculated as per Nguyen, et al. [35].

\section{Chlorophyll A and B Estimation}

For this set of experiment the larvae were allowed to feed on leaves for seven days in the clip cage. Fifth leaf of the damaged and undamaged plants was removed and $0.1 \mathrm{~g}$ leaf was homogenized in $10 \mathrm{ml}$ of $80 \%$ acetone. The extract was centrifuged at $3000 \mathrm{rpm}$ for $10 \mathrm{~min}$ at $4^{\circ} \mathrm{C}$. The supernatant was used for absorbance at 663 and $645 \mathrm{~nm}$ for calculating $\mathrm{Chl}$ a and $\mathrm{b}$ according to the equations given by Arnon, et al. [36].

\section{Larval Preference Assay}

Fifth leaf of each of the four treated plant sets (after $48 \mathrm{~h}$ of insect damage) was removed and their leaf area was measured as per $0^{\prime} \mathrm{Neal}$, et al. [32]. One leaf per treatment set was placed at equal distance in a $20 \mathrm{~cm}$ diameter Petri dish. Four S. litura of third instar were released at the centre of the plate for $24 \mathrm{~h}$. The insects were satiated with water for $12 \mathrm{~h}$ before the experiment. Leaf area was measured again after feeding to calculate the amount of leaf consumed from each set.

\section{Insect Performance Assays}

Fifth leaves of each set were placed individually in containers lined with moist filter paper. Four containers, each for the leaves of one set, were kept without larvae to determine leaf moisture loss. Initial weight of the leaves was observed before placing then separately in $9 \mathrm{~cm}$ Petriplates lined with Whatmann No.1 filter paper. Each of these plates received one newly moulted final instar larvae, which were satiated with water overnight. Larval weight gain and the weight of the remaining leaf were observed after $24 \mathrm{~h}$ of feeding. The leaf weight at the end 
of each experiment was subtracted from its initial weight to calculate the amount ingested. Change in leaf weight due to loss of moisture was determined from leaves in containers without larvae and deducted from the experimental and control leaves.

Nutritional indices were calculated as per Waldbauer, et al. [37] as follows:

The Waldbauer indices were calculated as follows: Consumption Index $(\mathrm{CI})=[($ leaf mass ingested $) /($ larval mass gain $\mathrm{x}$ number of days)], Approximate Digestibility $(\mathrm{AD})=[$ (leaf mass ingested- frass mass $) /$ (leaf mass ingested)], Efficiency of Conversion of Digested food (ECD) $=[$ (larval mass gain) $/$ (leaf mass ingested- frass mass) $]$ and Efficiency of Conversion of Ingested food (ECI)= [(larval mass gain)/(leaf mass ingested)].

\section{Statistical Analysis}

Data were analyzed using SPSS 23 (IBM Chicago, IL, USA). Data normality and homogeneity of variance was determined using one-sample Kolmogorov-Smirnov test and Levene's test, respectively. Trichome number and PPO data was normalized by log transformation whereas SOD and GR data was normalised using square root transformation. Trichome number and dry weight data was analysed by using one way ANOVA with LSD as post hoc treatment. Larvae preference was analysed using non-parametric $\chi 2$ Friedman's test.

\section{Results}

Trichome number was higher on the adaxial as well as abaxial surface of tomato leaf in PSB supplemented plants (Table 1). Glandular trichomes were significantly increased on both the surfaces, with PSB supplementation especially upon insect damage (Univariate ANOVA; Adaxial $\mathrm{F}(3,39)=72.631, \mathrm{P}<0.001 ;$ Abaxial $\mathrm{F}(3,39)=36.855$, $\mathrm{P}<0.001$ ). Irrespective of insect damaged, non-glandular trichome number was higher in PSB supplemented plants in comparison to control plants (Univariate ANOVA; Adaxial $\mathrm{F}(3,39)=9.427, \mathrm{P}<0.001$; Abaxial $\mathrm{F}(3,39)=7.528$, $\mathrm{P}<0.001$ ). On the contrary, unsupplemented control plants showed no significant difference in trichome number upon insect damage, except for non-gladular trichomes on the adaxial surface $(\mathrm{P}=0.021)$. Insect damage positively influenced trichome number in both control and PSB supplemented plants $(\mathrm{P}=0.001)$.

\begin{tabular}{|c|c|c|c|c|}
\hline & Glandular adaxial & Glandular abaxial & Non glandular adaxial & Non glandular abaxial \\
\hline Control Undamaged & $17.0 \pm 2.46^{\mathbf{c}}$ & $12.5 \pm 1.38^{\mathbf{d}}$ & $10.4 \pm 1.55^{\mathbf{b}}$ & $28.4 \pm 3.93^{\mathbf{b}}$ \\
\hline Control damaged & $12.2 \pm 0.85^{\mathbf{c}}$ & $25.4 \pm 2.36^{\mathbf{c}}$ & $18.7 \pm 3.331^{\mathbf{a}}$ & $28.0 \pm 3.34^{\mathbf{b}}$ \\
\hline PSB Undamaged & $51.9 \pm 5.92^{\mathbf{b}}$ & $39.7 \pm 1.52^{\mathbf{b}}$ & $10.9 \pm 5.93^{\mathbf{b}}$ & $51.3 \pm 5.67^{\mathbf{a}}$ \\
\hline PSB damaged & $80.8 \pm 3.22^{\mathbf{a}}$ & $74.0 \pm 4.64^{\mathbf{a}}$ & $28.7 \pm 3.61^{\mathbf{a}}$ & $46.1 \pm 4.57^{\mathbf{a}}$ \\
\hline
\end{tabular}

Mean followed by similar letter(s) in each column, are not significantly different at $0.05 \%$ level of probability according to LSD Test.

Table 1: ANOVA table of trichomes on adaxial and abaxial surface of newly emerged leaf of tomato plant after 7 days of damage (mean $\pm \mathrm{SE}$ ).

Mean fresh weight of the four treatments did not change significantly. However, dry weight increased significantly in PSB supplemented plants irrespective of insect damage (Univariate ANOVA; $\mathrm{F}(1,3)=6.357, \mathrm{P}<0.001$ ) (Table 2). Further, shoot dry weight also increased significantly with insect damaged $(\mathrm{P}=0.029)$. This difference was prominently observed in damaged PSB supplemented compared to damaged control plants $(\mathrm{P}<0.001)$.

\begin{tabular}{|c|c|c|c|}
\hline Treatments & Shoot & Root & Total \\
\hline Control Undamaged & $0.72 \pm 0.014^{\mathbf{c}}$ & $0.16 \pm 0.004$ & $3.34 \pm 0.068$ \\
\hline Control Damaged & $1.20 \pm 0.027^{\mathbf{b}}$ & $0.22 \pm 0.004$ & $3.30 \pm 0.159$ \\
\hline PSB Undamaged & $1.20 \pm 0.026^{\mathbf{b}}$ & $0.20 \pm 0.005$ & $3.70 \pm 0.091$ \\
\hline PSB Damaged & $1.40 \pm 0.028^{\mathbf{a}}$ & $0.23 \pm 0.04$ & $3.44 \pm 0.109$ \\
\hline
\end{tabular}

Mean fallowed by similar letter(s) in each column, are not significantly different at $0.05 \%$ level of probability according to LSD Test. PSB means Phosphate Solubilizing Bacteria, Damaged means insect damaged and Undamaged means not damaged.

Table 2: Mean (+ SE, N=22) ANOVA table for shoot and root dry weight of control and PSB supplemented plants.

Mathur V, et al. Microbial Fertilizer Improves Constitutive and Induced Resistance of 
SOD levels in undamaged control plants were significantly high compared to the other three treatments at $3 \mathrm{~h}$ (Univariate ANOVA; $\mathrm{F}(3,36)=20.729, \quad \mathrm{P}<0.001$ ) (Figure 1a). On the contrary, at 9h SOD increased in damaged control and undamaged PSB plants (Univariate ANOVA; $F(3,36)=38.857, \quad \mathrm{P}<0.001)$. Moreover, at $9 \mathrm{~h}$, damaged PSB supplemented and control undamaged plants showed equivalent levels of SOD which were significantly low than damaged control $(\mathrm{P}<0.001)$ and undamaged PSB plants $(\mathrm{P}<0.001)$.There was no significant change in the GR activity in the four treatments at $3 \mathrm{~h}$ (Univariate ANOVA; $\mathrm{F}(1,26)=2.009, \quad \mathrm{P}=0.057$ ) (Figure 1b). Moreover, GR significant increased from $3 \mathrm{~h}$ to $9 \mathrm{~h}$ in insect damaged unsupplemented control plants only (Univariate ANOVA; $\mathrm{F}(1,66)=3.288, \mathrm{P}<0.005$ ). The enzyme activity in this set showed a drastic increase in at 9h (Univariate ANOVA; $\mathrm{F}(3,26)=6.323, \mathrm{P}<0.002$ ). Further, at $9 \mathrm{~h} \mathrm{GR}$ activity tends to increase in insect damaged unsupplemented plants compared with undamaged control plant $(\mathrm{P}=0.073)$. Also, in PSB supplemented plants as well GR significantly increased with insect damage at $9 \mathrm{~h}(\mathrm{P}=0.001)$. At $48 \mathrm{~h}$, the presence of PPO in undamaged control plants was negligible. However, PPO increased with insect damaged in both control and PSB plants (Figure 1c).

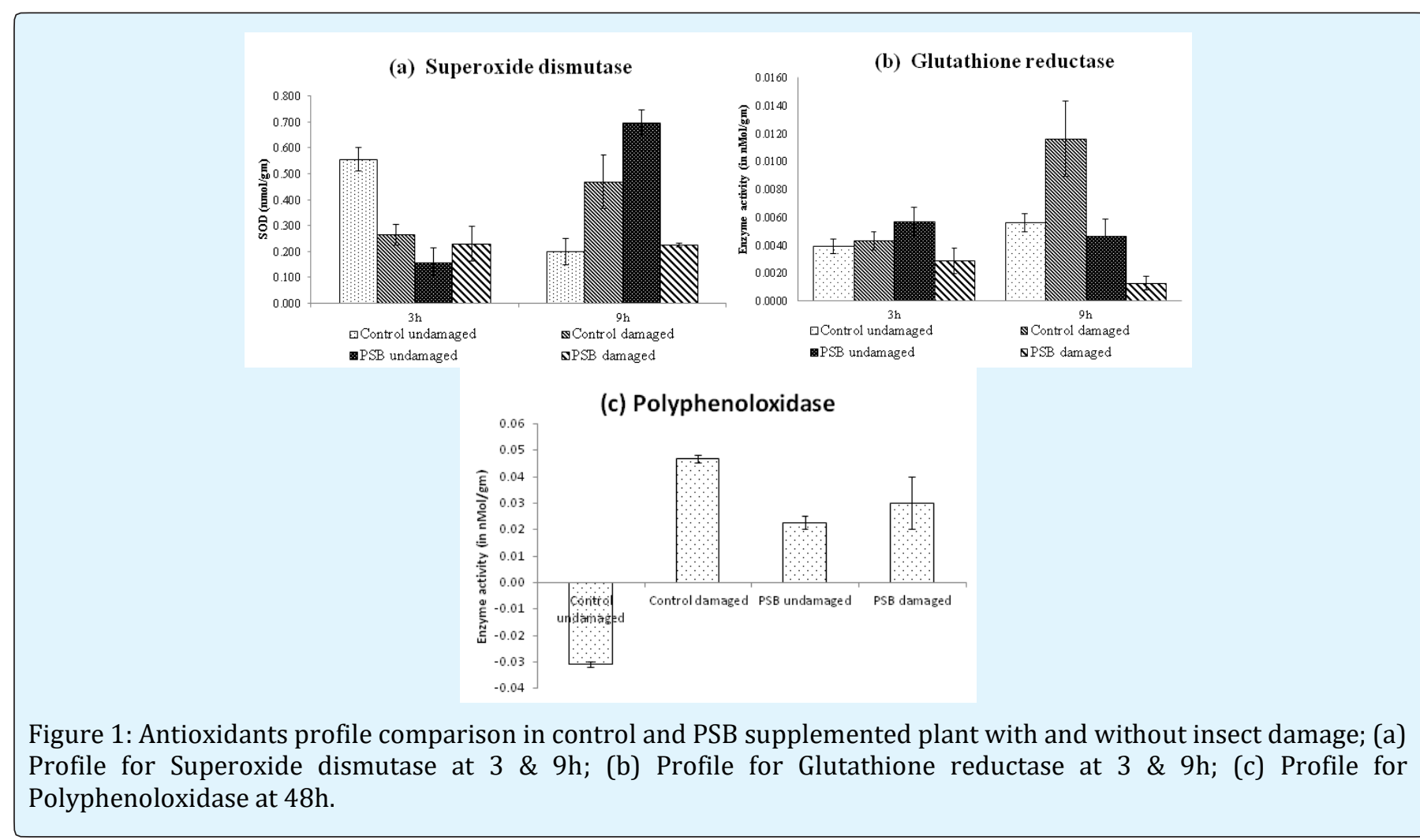

Among the two types of chlorophylls only chlorophyll a levels were significantly high in undamaged control plants compared the other treatments (Univariate ANOVA;
$F(3,27)=3.905, P<0.05$ ) (Table 3). No significant changes in Chlorophyll a \& b levels were found with the other three treatments (Univariate ANOVA; $F(3,27)=0.168$ ).

\begin{tabular}{|c|c|c|}
\hline Treatments & Chl $\boldsymbol{a}$ & Chl $\boldsymbol{b}$ \\
\hline Control Undamaged & $38.5 \pm 1.46^{\mathbf{a}}$ & $35.8 \pm 1.23$ \\
\hline Control Damaged & $35.3 \pm 0.31^{\mathbf{b}}$ & $35.1 \pm 1.57$ \\
\hline PSB Undamaged & $35.3 \pm 0.20^{\mathbf{b}}$ & $34.1 \pm 1.06$ \\
\hline PSB Damaged & $34.5 \pm 1.00^{\mathbf{b}}$ & $34.7 \pm 2.81$ \\
\hline
\end{tabular}

Mean fallowed by similar letter(s) in each column, are not significantly different at $0.05 \%$ level of probability according to LSD Test. PSB means Phosphate Solubilising Bacteria, Damaged means insect damaged and Undamaged means not damaged.

Table 3: Mean (+ SE, N=7) chlorophyll a and b content in mg/0.1g fresh leaf of tomato. 


\section{International Journal of Zoology and Animal Biology}

In choice based larval preference assay, feeding area was least on PSB supplemented plant that was previously damaged. However, there was no significant difference between all treatments in amount of leaf area consumed (Table 4).

\begin{tabular}{|c|c|c|c|c|}
\hline Treatments & $\mathbf{N}$ & Leaf consumed & $\boldsymbol{\chi 2}$ & $\mathbf{P}$ \\
\hline Control undamaged & 10 & $39.0 \pm 8.27$ & 3.143 & 0.958 \\
\hline Control damaged & 10 & $39.0 \pm 6.22$ & 0.833 & 1 \\
\hline Bacteria undamaged & 10 & $40.5 \pm 5.33$ & 1.333 & 0.998 \\
\hline Bacteria damaged & 10 & $21.7 \pm 4.88$ & 2.667 & 0.914 \\
\hline
\end{tabular}

$\chi 2$ Friedman test: $\mathrm{P}<0.05$.

Table 4: Percentage $(+\mathrm{SE}, \mathrm{n}=10)$ of differently treated tomato leaf consumed by third instar $S$. litura during leaf preference assay.
Larval consumption was highest on previously damaged control plant leaf whereas the least consumption was observed on damaged PSB (Table 5). Larvae weight gain was highest on PSB undamaged plants followed by control undamaged, control damaged and damaged PSB bacteria damaged after $24 \mathrm{~h}$ of insect feeding. The result from efficiency of conversion of digested food to body shows that larvae converted high amount of consumed food from PSB supplemented undamaged and damaged leaf (173.1 and 136.5\% respectively). Larva utilized high percentage of ingested food from undamaged plant compared to previously damaged plants.

\begin{tabular}{|c|c|c|c|c|}
\hline & $\begin{array}{c}\text { Control } \\
\text { undamaged }\end{array}$ & $\begin{array}{c}\text { Control } \\
\text { damaged }\end{array}$ & PSB undamaged & PSB damaged \\
\hline Larval weight gain (g) & $0.04^{\mathrm{a}} \pm 0.002$ & $0.03^{\mathrm{b}} \pm 0.01$ & $0.04^{\mathrm{a}} \pm 0.02$ & $0.01^{\mathrm{c}} \pm 0.003$ \\
\hline Consumption index (g g-1 day -1) & $0.06^{\mathrm{c}} \pm 0.01$ & $0.17^{\mathrm{a}} \pm 0.01$ & $0.08^{\mathrm{c}} \pm 0.02$ & $0.12^{\mathrm{b}} \pm 0.03$ \\
\hline Approximate digestibility (\%) & $57.60^{\mathrm{c}} \pm 6.00$ & $173.40^{\mathrm{a}} \pm 5.50$ & $70.60^{\mathrm{b}} \pm 9.10$ & $52.3^{\mathrm{c}} \pm 8.10$ \\
\hline Efficiency of conversion of digested food (\%) & $69.90^{\mathrm{b}} \pm 34.10$ & $40.80^{\mathrm{b}} \pm 5.60$ & $173.10^{\mathrm{a}} \pm 46.70$ & $136.5^{\mathrm{b}} \pm 49.20$ \\
\hline Efficiency of conversion of ingested food (\%) & $81.70^{\mathrm{a}} \pm 9.33$ & $25.10^{\mathrm{c}} \pm 0.86$ & $68.20^{\mathrm{a}} \pm 11.34$ & $42.7^{\mathrm{b}} \pm 8.99$ \\
\hline
\end{tabular}

Table 5: Mean \pm SE $(n=10)$ nutritional indices of Spodoptera litura in bacteria supplemented and control plant leaves.

\section{Discussion}

When plants are stressed by biotic or abiotic factors, major physiological and morphological changes are induced and plant resistance mechanisms are generally activated. In spite of major advances in our understanding of the plant responses, little information is available on how PSB supplementation affects induced responses. Through present study we found a positive simulation in number of trichomes present in PSB supplemented plants with almost 2 times increase in granular trichomes. These trichomes further increased with insect damaged on PSB supplemented plants to $>4$ times on both adaxial as well as abaxial surface. Glandular trichomes have heads containing various sticky and/or toxic exudates that may be secreted onto the plant surface or may rupture on contact with herbivores, causing irritation, entrapment, or death Simmons and Gurr, et al. [38]. Plant uses these structures as resistance mechanism against biotic as well as abiotic stresses. Furthermore, our results also indicated a significant increase in non-glandular trichomes was also observed in insect damaged PSB supplemented plants. Unlike glandular trichomes, nonglandular trichomes do not have such heads, but they affect herbivores by mechanically obstructing their movement across the plant surface [38].
Our results also showed that PSB supplementation substantially increased shoot growth and development of tomato plant in terms of increased shoot biomass. Increased plant biomass due to microbial fertilizer administration in various crops is well documented [3941]. Our study indicated increased shoot biomass in insect damaged plants of both control as well as PSB supplemented. This may be due to increased allocation of dry mass towards shoot as a mean of compensatory mechanism to maintain functional shoot at the expense of root [40]. Water retention in shoots of PSB supplemented plants was higher than unsupplemented undamaged control plants. However, interestingly water retention in root and shoot was higher in insect damaged control plants compared to the other three sets of treatments (supplementary data).

The amount of chlorophyll a was found to be elevated compared to chlorophyll b. Chlorophyll a is recognized as the main pigments which convert light energy into chemical energy. Chlorophyll $b$ as accessory pigments acts indirectly in photosynthesis by transferring the light it absorbs to chlorophyll a [43]. These help tomato plant to capture and convert more light energy to chemical energy. Further, unsupplemented plants without insect damaged show a significantly higher Chlorophyll a, on the contrary 


\section{International Journal of Zoology and Animal Biology}

rest of the three treatments has similar levels. When comparing these results to induction of trichomes (Table 1 ), the pattern is reversed which may be attributed to nutritional allocation from plant physiological processes to defence.

During insect preference assays larvae consumed less percentage of leaf area from PSB supplemented plants with insect damage than all three treatment plants however, there was no significant difference between all treatments. Less percentage consumption from PSB supplemented plant leaf is due to induced toxic secondary metabolites from previous insect damage. Previous studies have indicated that after a prior attack by herbivores, plants can be induced to increase their polyphenol oxidase activity, which decreases the nutrient value of the foliage and reduces the feeding preference of the insects [44-46].

Our results indicate no significant change in antioxidants (SOD and GR) post $3 \mathrm{~h}$ of insect damage. However, in case of control damaged plants antioxidants increased after $9 \mathrm{~h}$. This indicates that even though oxidative stress initiates within minutes of insect feeding [47], our results suggest a systemic antioxidants response in tomato is generated only after $9 \mathrm{~h}$. Being sensitive to metabolic fluctuations, SOD is the part of first line of defense in case of biotic and abiotic stress, where its levels had been reported to increase [48]. Contrary to unsupplemented treatment, plants with PSB supplementation did not indicate elevated SOD or GR levels at $9 \mathrm{~h}$, indicating susceptibility to insect induced oxidative damaged at early hours. Moreover, increased GR helps the plant in up regulating cells glutathione pool to improve stress tolerance [49]. On the contrary, PPO activity significantly increased in PSB damaged plants at $48 \mathrm{~h}$ which indicates activation of resistance mechanism against insect induced oxidative stress at this time point. PPO catalysis oxidation of polyphenols to quinones and activates defense against insects [50]. This is also evident in damaged control plants at this time. Although after comparing the overall antioxidant profile, PSB supplementation does not indicate positive effect on insect induced oxidative stress.

Larval weight gain on undamaged plant leaf on both sets of control as well PSB supplemented plants compared to damaged ones. Specifically, PSB supplemented damaged plants showed least larval weight gain although consumption index in these plats was next to highest among the four sets. Subsequently, percentage approximate digestibility of PSB supplemented plants with insect damage was least. Possible reason for this feeding behaviour is the presence of increased level of glandular trichomes observed in these treatments which increases insect resistance. Moreover, the presence of defence related metabolites (such as $\alpha$ tomatin and rutin) in tomato plant, which reduces the quality of food [51]. Also, after having been damaged by insect feeding, plants increase their polyphenol oxidase activity and reduce their foliar carbohydrate concentrations. This increase in oxidase activity and decrease in carbohydrate content might decrease the nutritive value and thus reduce performance of subsequent feeding insects [45,46,52-54]. On the other hand control undamaged plants showed least consumption index but highest larval weight gain.

Although, PSB supplemented undamaged plants also showed high larval consumption and hence the percentage approximate digestibility, which shows improved nutritional quality in these plants resulting in increased palatability. Moreover, larvae consumed higher amount of food from damaged leaves than undamaged one. This is may be because of damage by insect releases some volatile chemicals which initiate subsequent insect to choose first.

The result from efficiency of conversion of digested food shows that higher percentage of digested food was converted in to larvae body from PSB supplemented undamaged plants. This is related with higher weight gain of larvae from PSB supplemented undamaged plants. Conversion of ingested food to larvae body was higher from undamaged plants. This is because in damaged plants defensive toxic chemicals are higher and larvae eliminate these toxic substances through excretion rather than converting in to the body.

Compared to insect damaged control plant lacking PSB supplementation, tomato plants with PSB administration in tomato shows a positive effect on its insect induced responses. At early hours of insect exposure, both these plants showed equal susceptibility to oxidative stress. Although contrary to unsupplemented plants, PSB plants after $48 \mathrm{~h}$ of insect damage, showed an increased mechanical resistance towards insect in terms of elevated trichome number. However, biochemical responses in these plants at $48 \mathrm{~h}$ showed no significant change, which is indicated by both chlorophyll and PPO profiles. On the other hand, when growth period of tomato in PSB is prolonged, a positive effect on shoot biomass is observed after $48 \mathrm{~h}$ of insect damage. Insect feeding behaviour towards these plants indicated a decline in larval weight gain on previously damaged plants. However, an increased consumption index does indicate increased palatability of the plant, possibly due to high phosphorus 


\section{International Journal of Zoology and Animal Biology}

availability. Corresponding to the increased consumption index reduced efficiency of ingested food conversion was observed.

Therefore, results indicate that PSB administration improves growth as well as induced resistance in the tomato, which further aids in increasing growth period with PSB. However, in order to understand intricate mechanisms underlying the microbial fertilizer-plantinsect interactions field based studies in this direction are required. Also, an effective implementation of these microbial fertilizers in sustainable practices can be formulated based on their interactions with the rhizospheric microbiota.

\section{Acknowledgement}

The authors would like to acknowledge NAM S\&T centre for granting RTF-DCS fellowship 2015 to Mr. Melesse Angulo Torro for this work. The authors would also like to thank the post graduate students involved with the experimentation and observation of various experiments.

\section{References}

1. Karban R, Myers JH (1989) Induced plant responses to herbivory. Annual Review of Ecology and Systematics 20: 331-348.

2. Dicke M, Hilker M (2003) Induced plant defences: from molecular biology to evolutionary ecology. Basic and Applied Ecology 4(1): 3-14.

3. Zangerl AR (2003) Evolution of induced plant responses to herbivores. Basic and Applied Ecology 4(1): 91-103.

4. Redman AM, Cipollini DF, Schultz JC (2001) Fitness costs of jasmonic acid-induced defense in tomato, Lycopersicon esculentum. Oecologia 126(3): 380-385.

5. Bryant JP, Chapin FS, Klein DR (1983) Carbon/nutrient balance of boreal plants in relation to vertebrate herbivory. Oikos 40(3): 357-368.

6. Herms DA, Mattson WJ (1992) The dilemma of plants: to grow or to defend. The Quarterly Review of Biology 67(3): 238-335.

7. Hemming JDC, Lindroth RL (1999) Effects of light and nutrient availability on aspen: growth, phytochemistry, and insect performance. Journal of Chemical Ecology 25(7): 1687-1714.

8. Altieri MA, Nicholls CI (2003) Soil fertility management and insect pests: harmonizing soil and plant health in agroecosystems. Soil and Tillage Research 72(2): 203-211.

9. Mevi-Schütz J, Goverde M, Erhardt A (2003) Effects of fertilization and elevated $\mathrm{CO} 2$ on larval food and butterfly nectar amino acid preference in Coenonympha pamphilus L. Behavioral Ecology and Sociobiology 54(1): 36-43.

10. Myers JH (1985) Effect of physiological condition of the host plant on the ovipositional choice of the cabbage white butterfly, Pieris rapae. Journal of Animal Ecology 54: 193-204.

11. Ehrlich HL (1990) Mikrobiologische und biochemische Verfahrenstechnik. In: Einsele A, Finn RK, Samhaber W, (Eds.), Geomicrobiology, Weinheim: VCH, Germany.

12. Sample EC, Soper RJR (1980) The role of phosphorus in agriculture. In: Khasawneh FE, Sample EC, Kamprath EJ, (Eds.), Reactions of phosphate fertilizers in soils Madison, American Society of Agronomy, Wisconsin, USA.

13. Bates TR, Lynch JP (2000) Plant growth and phosphorus accumulation of wild type and two root hair mutants of Arabidopsis thaliana (Brassicaceae). Am J Bot 87(7): 958-963.

14. RodriGuze H, Fraga R (1999) Phosphate solubilizing bacteria and their role in plant growth promotion. Biotechnol adv 17(4-5): 319-339.

15. Lett CN, Dewald LE, Horton J (2011) Mycorrhizae and soil phosphorus affect growth of Celastrus orbiculatus. Biological Invasions 13: 2339-2350.

16. Malik MA, Marschner P, Khan KS (2012) Addition of organic and inorganic $\mathrm{P}$ sources to soil-Effects on $\mathrm{P}$ pools and microorganisms. Soil Biology \& Biochemistry 49: 106-113.

17. Bashan Y, de-Bashan, LE (2005) Bacteria/plant growth-promotion. In: Hillel D, (Ed.), Encyclopedia of soils in the environment, Elsevier, Oxford, UK, pp: 103-115. 


\section{International Journal of Zoology and Animal Biology}

18. Glick BR (2004) Bacterial ACC deaminase and the alleviation of plant stress. Adv Appl Microbiol 56: 291-312.

19. Lai WA, Rekha PD, Arun AB, Young CC (2008) Effect of mineral fertilizer, pigmanure, and Azospirillum rugosum on growth and nutrient contents of Lactuca sativa L. Biology and Fertility of Soils 45: 155-164.

20. Sharma SB, Sayyed RZ, Trivedi MH, Gobi TA (2013) Phosphate solubilizing microbes: sustainable approach for managing phosphorus deficiency in agricultural soils. Springer plus 2(1): 587.

21. Figueiredo MVB, Seldin L, de Araujo FF, Mariano RLR (2010) Plant growth Promoting rhizobacteria: fundamentals and applications. Microbiology Monographs 18: 21-43.

22. Ramamoorthy V, Viswanathan R, Raguchander $T$, Prakasam V, Samiyappan R (2001) Induction of systemic resistance by plant growth promoting rhizobacteria in crop plants against pests and diseases. Crop Protection 20(1): 1-11.

23. Zehnder G, Kloepper J, Yao C, Wei G (1997) Induction of systemic resistance in cucumber against cucumber beetles (Coleoptera: Crysomelidae) by plant-growthpromoting- rhizobacteria. Journal of Economic Entomology 90(2): 391-396.

24. Sikora RA (1988) Interrelationship between plant health promoting rhizobacteria, plant parasitic nematodes and soil microorganisms. Med Fac Landbouww Rijksuniv Gent 53: 867-878.

25. FAOSTAT F (2004) Statistics database.

26. Riahi A, Hdider C, Sanaa M, Tarchoun N, Ben Kheder $\mathrm{M}$, et al. (2009) Effect of conventional and organic production systems on the yield and quality of field tomato cultivars grown in Tunisia. Journal of the Science of Food and Agriculture 89(13): 2275-2282.

27. Asgedom S, Struik PC, Heuvelink E, Araia W (2011) Opportunities and constraints of tomato production in Eritrea. African Journal of Agricultural Research 6(4): 956-967.

28. Cai F, Chen W, Wei Z, Pang G, Li R, et al. (2015) Colonization of Trichoderma harzianum strain SQRT037 on tomato roots and its relationship to plant growth, nutrient availability and soil micro flora. Plant and soil 388(1-2): 337-350.
29. Bano A, Muqarab R (2017) Plant defence induced by PGPR against Spodoptera litura in tomato (Solanum lycopersicum L.). Plant Biol 19(3): 406-412.

30. Mpanga I, Dapaah H, Geistlinger J, Ludewig U, Neumann G (2018) Soil Type-Dependent Interactions of P-Solubilizing Microorganisms with Organic and Inorganic Fertilizers Mediate Plant Growth Promotion in Tomato. Agronomy 8(10): 213.

31. Lancashire PD, Bleiholder H, Boom TVD, Langelüddeke $P$, Stauss R, et al. (1991) A uniform decimal code for growth stages of crops and weeds. Annals of applied Biology 119(3): 561-601.

32. O' Neal ME, Landis DA, Isaacs R (2002) An inexpensive, accurate method for measuring leaf area and defoliation through digital image analysis. Journal of Economic Entomology 95(6): 1190-1194.

33. Verma VK, Rani KV, Sehgal N, Prakash O (2012) Immunostimulatory response induced by supplementation of Ficus benghalensis root powder, in the artificial feed the Indian freshwater murrel, Channa punctatus. Fish shellfish immunol 33(3): 590596.

34. Rao MV, Paliyath G, Ormrod DP, Murr DP, Watkins CB (1997) Influence of salicylic acid on $\mathrm{H} 202$ production, oxidative stress, and H202-metabolizing enzymes (salicylic acid-mediated oxidative damage requires H202). Plant Physiol 115(1): 137-149.

35. Nguyen D (2016) Interactions between biotic and abiotic stress responses in Solanum dulcamara. From molecular mechanisms to ecological consequences. [Sl: sn], pp: 210.

36. Arnon D (1949) Copper Enzymes in Isolated Chloroplasts. Polyphenoloxidase in Beta vulgaris. Plant Physiol 24(1): 1-15.

37. Waldbauer GP (1968) The consumption and utilization of food by insects. Advanced Insect Physiology 5: 229-288.

38. Simmons AT, Gurr GM (2004) Trichome-based host plant resistance of Lycopersicon species and the biocontrol agent Mallada signata: are they compatible? Entomologia experimentalis et applicata 113(2): 95-101.

39. Mahfouz SA, Sharaf-Eldin MA (2007) Effect of mineral vs. biofertilizer on growth, yield, and essential oil 
content of fennel (Foeniculum vulgare Mill.). International Agrophysics 21(4): 361-366.

40. Gholami A, Shahsavani S, Nezarat S (2009) The effect of plant growth promoting rhizobacteria (PGPR) on germination, seedling growth and yield of maize. International Journal of Life-Sciences Scientific Research 3(1): 35-40.

41. Prasanna R, Nain L, Ancha R, Srikrishna J, Joshi M, et al. (2009) Rhizosphere dynamics of inoculated cyanobacteria and their growth-promoting role in rice crop. Egyptian Journal of Biology 11: 26-36.

42. Crawley MJ (1983) Herbivory. The dynamics of animal-plant interactions. Blackwell Scientific Publications, UK, pp: 437.

43. Costache MA, Campeanu G, Neata G (2012) Studies concerning the extraction of chlorophyll and total carotenoids from vegetables. Romanian Biotechnological Letters 17(5): 7702-7708.

44. Felton GW, Donato KK, Broadway RM, Duffey SS (1992) Impact of oxidized plant phenolics on the nutritional quality of dietar protein to a noctuid herbivore, Spodoptera exigua. Journal of Insect Physiology 38(4): 277-285.

45. Stout MJ, Duffey SS (1996) Characterization of induced resistance in tomato plants. Entomologia experimentalis et applicata 79(3): 273-283.

46. Bostock RM, Karban R, Thaler JS, Weyman PD, Gilchrist D (2001) Signal interactions in induced resistance to pathogens and insect herbivores. European Journal of Plant Pathology 107(1): 103111.
47. Torres MA (2010) ROS in biotic interactions. Physiol Plant 138(4): 414-429.

48. Racchi ML (2013) Antioxidant defenses in plants with attention to Prunus and Citrus spp. Antioxidants 2(4): 340-369.

49. Garg N, Manchanda G (2009) ROS generation in plants: boon or bane?. Plant Biosystems 143(1): 8196.

50. El Khallal SM (2007) Induction and modulation of resistance in tomato plants against Fusarium wilt disease by bioagent fungi (arbuscular mycorrhiza) and/or hormonal elicitors (jasmonic acid \& salicylic acid): 2-changes in the antioxidant enzymes, phenolic compounds and pathogen related-proteins. Australian Journal of Basic and Applied Sciences 1(4): 717-732.

51. Kennedy GG (2003) Tomato, pests, parasitoids, and predators: tritrophic interactions involving the genus Lycopersicon. Annu rev entomol 48(1): 51-72.

52. Felton GW, Donato K, Delvecchio RJ, Duffey SS (1989) Activation of plant foliar oxidases by insect feeding reduces nutritive quality of foliage for noctuid herbivores. Journal of Chemical Ecology 15(12): 2667-2694.

53. Simpson SJ, Raubenheimer D (2001) The geometric analysis of nutrient-allelochemical interactions: a case study using locusts. Ecology 82(2): 422-439.

54. Lee KP, Behmer ST, Simpson SJ, Raubenheimer D (2002) A geometric analysis of nutrient regulation in the generalist caterpillar Spodoptera littoralis (Boisduval). J Insect Physiol 48(6): 655-665. 